\title{
AS REFORMAS NECESSÁRIAS AO ENSINO SECUNDÁRIO BRASILEIRO NOS ANOS 1950, SEGUNDO A REVISTA BRASILEIRA DE ESTUDOS PEDAGÓGICOS
}

Katya Zuquim Braghini*

Bruno Bontempi Junior**

RESUMO: Neste artigo, propõe-se uma análise dos artigos sobre o ensino secundário, publicados na Revista Brasileira de Estudos Pedagógicos (RBEP) ao longo dos anos de 1950. Investigam-se as críticas feitas por seus colaboradores à organização dada pela Lei Orgânica do Ensino Secundário (1942) a ramo do ensino médio, assim como as principais propostas de reforma, visando a torná-lo mais ativo, mais prático e mais popular. O objetivo principal é investigar que novo padrão de ensino secundário se projetava da combinação dos argumentos, como ideal para o ensino secundário brasileiro nos anos 1950. Tais necessidades se justificavam pela ideia de que o mundo vinha sendo regido por "novos imperativos" culturais, que a escola brasileira deveria adotar a fim de fomentar o desenvolvimento do país.

Palavras-chave: Ensino Secundário; Educação como Ação Política; Periódico Educacional.

\section{THE NECESSARY REFORMS TO THE BRAZILIAN SECONDARY SCHOOL IN THE 1950S ACCORDING TO THE REVISTA BRASILEIRA DE ESTUDOS PEDAGÓGICOS}

ABSTRACT: This article proposes an analysis of the articles on secondary school published in the Revista Brasileira de Estudos Pedagógicos (RBEP, Brazilian Journal of Pedagogical Studies) over the 1950s. The study investigates the criticism made by its collaborators to the organization provided by the Lei Orgânica do Ensino Secundário (Organic Law of Secondary School; 1942) to middle school, as well as the main proposals of reform, in an attempt to make it more active, practical and popular. The main objective is to investigate which was the new standard of secondary education being projected from the combination of arguments as the ideal in Brazil in the 1950s. Such needs were justified by the idea that the world was being ruled by "new cultural imperatives" that should be adopted by the Brazilian school in order to encourage the development of the country.

Keywords: Secondary School; Education as Political Action; Educational Journal.

\footnotetext{
*Doutora em Educação pela Pontifícia Universidade Católica de São Paulo (PUC-SP) e Pós-doutoranda do Grupo de Estudos e Pesquisas em História da Educação (GEPHE) da Universidade Federal de Minas Gerais (UFMG). E-mail: katya.braghini@yahoo.com.br * *Doutor em Educação pela Pontifícia Universidade Católica de São Paulo (PUC-SP) e Professor do Departamento de Filosofia da Educação e Ciências da Educação da Faculdade de Educação da Universidade de São Paulo (FE-USP). E-mail: bontempi@usp.br
} 


\section{INTRODUCุÃO}

Tendo como principal base documental os artigos sobre o ensino secundário publicados na Revista Brasileira de Estudos Pedagógicos (RBEP) durante a década de 1950, neste artigo são investigadas as críticas dirigidas por seus colaboradores à organização deste ramo do ensino médio, consagrada pela Lei Orgânica do Ensino Secundário (1942) ${ }^{1}$. Os colaboradores da RBEP, pautados na crença de que havia "novos imperativos culturais" a ser cumpridos para o alinhamento do país ao mundo desenvolvido, defenderam que a escola brasileira deveria ser substantivamente reformada, a fim de que o ensino secundário se tornasse mais ativo, mais prático e mais popular, de forma a desprestigiar progressivamente um tipo de educação voltada para uma "elite condutora".

Tais necessidades se justificavam pela ideia de que o mundo vinha sendo regido por "novos imperativos" culturais que a escola brasileira deveria adotar a fim de fomentar o desenvolvimento do país. Entre os "novos imperativos" que serão discutidos ao longo do artigo, podem ser citados o crescimento da população de jovens, as novas perspectivas educacionais relacionadas aos estudos sociológicos e antropológicos, as novas demandas econômicas que recaem sobre os planos educacionais etc. O objetivo principal é investigar que novo padrão de ensino secundário se projetava da combinação dos argumentos, como ideal para o ensino secundário brasileiro nos anos 1950.

$\mathrm{Na}$ RBEP, periódico especializado em educação, o tema da "qualidade de ensino" é constante, aparecendo ora de um modo genérico, ora como fundamento de artigos, possuindo, assim, um infindável número de referências e muitas possibilidades de combinação com outras variáveis da educação. Já o ensino secundário é tratado como um particular nível de ensino, do que decorre ter sido objeto de uma boa quantidade de escritos, em que a questão da qualidade encontra-se diretamente implicada.

Assim, deu-se preferência aos artigos que tinham estampado em título a expressão "ensino secundário", conforme os exemplos: "Uma batalha do ensino secundário paulista"; "Tendências antagônicas do ensino secundário brasileiro"; "Estruturação ideal do ensino secundário no Brasil" etc. Com este procedimento, foi possível delimitar a quantidade de textos a serem analisados, em favor da possibilidade de estudar a "qualidade de ensino" especificamente voltada para o "ensino secundário". 
Existe apenas uma pequena parcela do corpus documental que não seguiu este critério. Trata-se de textos cujos títulos evidenciavam a presença de alguns temas que se repetiam nos discursos sobre o ensino secundário, entre os quais, "desenvolvimento", "democracia", "liberdade". No aspecto quantitativo, tais textos não chegaram a contabilizar um montante expressivo, perfazendo um total de 6 textos, assim ordenados cronologicamente: Mensagem presidencial (Getúlio Vargas, 1952); Discurso de posse de Anísio Teixeira no Inep (Anísio Teixeira, 1952); Acerca do estudo eficiente (Rui Carrigton da Costa, 1953); Educação não é privilégio (Anísio Teixeira, 1956); Educação para o desenvolvimento (Lourenço Filho, 1961); e Educação e o desenvolvimento (Anísio Teixeira, 1961). O motivo da inclusão desses textos foi o enriquecimento qualitativo do trabalho, tendo em mente os temas que eram constantemente repetidos quando se falava em ensino médio brasileiro de qualidade nos anos $1950^{2}$.

O trabalho enfatizou os anos 1950. Entretanto, foi necessário "retornar" ao ano de fundação da RBEP, mais precisamente a 1944, procedimento que tem sua explicação à luz do objetivo anunciado deste trabalho, de dar destaque a um tema que se configurou, hipoteticamente, por meio da reordenação de "novos" e "velhos" significados

Por considerar que a constituição de padrões configuradores da “qualidade do ensino secundário nos anos 1950" não poderia ser uma discussão absolutamente nova, fez-se necessária uma incursão para tempos um pouco mais recuados, a fim de compreender, mais adequadamente, $\mathrm{o}$ tema central desta pesquisa. Foram trazidos à investigação outros textos relativos ao ensino secundário publicados na RBEP, mas em um período diverso. $\mathrm{O}$ trabalho com esses textos evidenciou a existência de estilo narrativo escolanovista, que, nos anos seguintes, foi renovado. Esse entendimento acabou enriquecendo a discussão de "qualidade" nos limites teóricos estabelecidos na constituição do problema.

Está-se falando de dois blocos temporais de textos, que aqui foram separados por meio de diagnósticos já estabelecidos por Gandini (1995) e Saavedra (1988). Essas pesquisadoras delinearam a periodização da RBEP segundo critérios analíticos, da forma como se segue.

O primeiro bloco diz respeito, no âmbito de produção da RBEP, ao período que compreende a metade final dos anos 40, em que o Inep foi dirigido por Lourenço Filho, e logo a seguir, por Murilo Braga. Na presente pesquisa, este período é chamado de primeira fase da RBEP. 
Saavedra (1988), ao estudar os "passos e descompassos" do Inep, acabou separando os períodos por gestões, considerando a gestão de Lourenço Filho e Murilo Braga como uma fase (1937-1952), e o período em que Anísio Teixeira esteve à frente do Instituto, entre 1952-1964, como um "segundo momento" do Inep. Para Gandini (1995, p. 15), em “[...] 1952 Anísio Teixeira assumiu a direção da RBEP e então se inaugurou uma nova fase que se estendeu até 1964 [...]". Neste momento, pode-se considerar o produto editorial do Inep, que é a RBEP, em sua segunda fase.

Os dois "blocos" que foram diferenciados para o estudo da fonte devem ser entendidos como momentos históricos diferenciados, com seus respectivos autores. São momentos de funcionamento de um órgão público, permeados por situações concretas que lhes concederam uma propriedade particular. Ao mesmo tempo, não devem ser entendidos como blocos abruptamente separados pela cronologia, já que, de certa forma, são períodos históricos que se mesclam pela permanência do tema e de certas preocupações de fundo. Há que se considerar, enfim, que esses dois blocos de textos são o universo documental estudado, fonte privilegiada da pesquisa.

Portanto, na primeira fase da RBEP, foram contados 21 artigos tendo o "ensino secundário" indicado no título. $\mathrm{Na}$ segunda fase, foram contados 27. Juntos contabilizam 48 artigos. Somados aos outros 6 artigos com temas diferenciados, já enunciados, foram contabilizados 54 artigos 4

Desses 54 textos, foi dada prioridade aos que foram publicados na seção Ideias e Debates, espécie de "cérebro do periódico", ou seja, a parte mais intelectualizada, local de publicação de mestres e teóricos tais como Anísio Teixeira, Lourenço Filho, Abgar Renault, entre outros intelectuais da educação. Também foi organizado um conjunto de textos publicados em outra seção da RBEP, Através de Revistas e Jornais, em que predominam artigos publicados em jornais e revistas educacionais especializadas, públicas ou empresariais. Preferencialmente, buscou-se pesquisar artigos que fossem resultados de trabalhos de órgãos ligados ao governo e cujos artigos eram repassados para a RBEP. Eventualmente, foram transpostos para a RBEP artigos de vários jornais brasileiros, sendo O Correio da Manhã o jornal preferencial. 


\section{CRÍTICA AO ENSINO PARA BACHARÉIS DIANTE DA NECESSIDADE DE “COMPREENSÃO DOS PROBLEMAS DA SOCIEDADE CONTEMPORÂNEA"}

Nos anos 1950, a organização do ensino secundário para a formação de uma elite condutora, segundo a Lei Orgânica do Ensino Secundário ${ }^{5}$, foi alvo de muitas críticas na Revista Brasileira de Ensino Pedagógico. A educação das "individualidades condutoras" passou a ser questionada, em nome de um ensino mais bem adaptado às necessidades daquele momento histórico, ou seja, mais ativo, mais prático e mais popular. Havia a crítica de que, para atender às demandas educacionais da sociedade brasileira, o governo vinha superpondo "decretos, portarias, instruções e circulares", formando uma "colcha de retalhos" que desorganizava ainda mais sua estrutura $^{6}$. Os artigos publicados na década de 1950 ressaltam o aparente consenso entre os colaboradores da RBEP em torno da ideia de que o mundo vinha sendo regido por "novos imperativos" culturais, que a escola deveria adotar a fim de poder operar segundo uma nova concepção de ensino. Para os seus colaboradores, era necessária uma reforma de costumes para que o prestígio dado a este nível de ensino alterasse sua finalidade, de formação das elites condutoras para uma formação média.

A associação valorativa entre o bom e o novo, e entre o mau e o velho, torna-se predominante nas abordagens do tema na RBEP, fundamentando a tese de que havia de redefinir a escola e seu ensino segundo as novas funções requeridas pela sociedade contemporânea ${ }^{7}$. Para a RBEP, a conexão de fatores sociais associados às sociedades industriais de massa, tais como o crescimento das camadas médias e a urbanização, havia tornado inadequado em seus currículos e métodos o ensino secundário em seu modelo tradicional. $\mathrm{O}$ ensino secundário teria de modificar a sua estrutura, a fim de acompanhar essa "grande mudança".

Antes mesmo dos anos 1950, a Revista já apontava para essa "tendência":

Apesar de, em várias ocasiões, surpreender-se na história da educação, realizações contrárias ao pensamento pedagógico predominante, podemos verificar que se introduzem, de tempos em tempos, as alterações nos sistemas educacionais, procurando-se dessa forma acompanhar a evolução das ideias e dos acontecimentos. [...] Em verdade, toda uma série complexa de elementos conexos constitui a fonte cujo potencial irá moldar a estrutura, em torno da qual girará o ensino secundário, capaz de satisfazer a interesses gerais. (BRASIL, 1946, p. 155). 
O imobilismo poderia acarretar consequências graves para os países que por ele optassem. Entendia-se que dessa mudança dependia a superação da condição de atraso do país (DUTRA, 1946, p. 6; SOUZA, 1947, p. 545). Especificamente no caso brasileiro, no editorial de julho de 1946, afirma-se que nos "últimos anos" seria necessária uma atitude "[...] mais objetiva ao ser procurada solução para os problemas vitais da sociedade brasileira [...]”. Sobre o ensino secundário e sua relação com as soluções objetivas, diz a RBEP (BRASIL, 1946, p. 227-228):

A unilateralidade com que seja encarada qualquer das faces desse prisma forçosamente leva-nos a concluir pela existência de grave crise no ensino, quando é certo que o Estado, no seu próprio interesse, procura incrementar o ensino secundário, quer determinando com precisão os seus fins, quer empregando todos os meios ao alcance para obtenção de maior rendimento.

Para Jaime Abreu, “[...] o problema crucial de educação na maioria dos países, hoje em dia, é o da reorganização do sistema educacional de nível secundário [...]" (ABREU, 1960, p. 4) ${ }^{8}$. O autor defendia a existência de uma "nova dimensão de universalização", e que as "[...] mudanças socioculturais haveriam de trazer, em seu âmago, tendências de várias espécies de ensino secundário[...]". Levando em conta a "dimensão da universalização", dizia Abreu que o mundo estava "inquieto" e que existiam elementos "corolários de uma época". Um desses "corolários” era a ideia de que o ensino secundário passasse a apresentar as "tendências de várias espécies", abandonando o ensino "bacharelesco", até alcançar essa diversidade de disposições (ABREU, 1960, p. 3-4).

Esses motivos já estavam presentes nos primeiros artigos sobre o tema no periódico. A educação com fins pragmáticos e científicos era parte do discurso da RBEP desde a segunda metade dos anos 1940. Em documento transcrito da publicação da União Panamericana (UP), em 1947, é exposta a "imperiosa necessidade de reformar, substancialmente, o programa da escola secundária norte-americana", porque as "novas descobertas científicas" davam muita amplitude aos programas do ensino secundário, pois“a escola secundária corresponde, mais do que nunca, à tarefa de preparar a nova geração na compreensão dos problemas da sociedade contemporânea.” (UNIÃO PANAMERICANA, 1947, p. 225). Nesse documento, a ideia principal da reforma do ensino secundário ancora-se no 
pressuposto de que a educação deveria preparar os jovens "para a escolha de uma carreira" (p. 237). A juventude precisava "aprender a trabalhar", pois, "apesar do [sic] trabalho ser parte essencial na vida do homem", ainda não "tinha sido incluído na organização da educação escolar.". Ainda de acordo com o documento, "a capacidade de trabalhar durante oito ou mais horas consecutivas, não era, de modo algum, um dom natural, mas, antes, uma qualidade que deveria ser adquirida". Por este motivo, o trabalho deveria "ser incorporado na reforma, no sentido de tornar mais fácil a transição da meninice para uma vida adulta", pois ele concederia ao jovem "confiança em si mesmo", "ânimo necessário para a vida prática” (p. 230-231).

Ainda de acordo com o artigo, os alunos agora procediam de todos os extratos populacionais e camadas sociais, e todos os planos "imagináveis" teriam sido feitos a fim de orientá-los para "ocupações futuras” (p. 205). Com os "preceitos da psicologia moderna", os jovens passariam a adquirir uma "compreensão de si mesmos" como organismos "psicobiológicos", o que os salvaria dos perigos de "um grande número de erros responsáveis por boa parte da infelicidade humana" e dos transtornos mentais e físicos que afligiam as pessoas no ambiente congestionado que caracterizaria a coletividade daqueles tempos (p. 235). Por esse motivo, os jovens deveriam ser "clarificados" por diversos tipos de "expressões e impressões", por meio das quais poderiam demonstrar com "segurança e qualidade" sua capacidade criadora, seus "potenciais de expressão" (p. 241). Esses seriam os fundamentos de uma nova dinâmica dos "Estudos Sociais", que, ao serem aplicados nas escolas, poderiam se tornar "uma das mais importantes contribuições da escola para a preparação dos jovens na luta pela vida”. Tais hábitos sociais poderiam ser adquiridos dentro ou fora das aulas do colégio, porque esse "treinamento" dependeria da prática social, vista como consequência da convivência infantil (UNIÃO PANAMERICANA, 1947, p. 233).

Em Ideias e Debates, há um artigo transcrito da Crônica das Organizações das Nações Unidas para a Educação, a Ciência e a Cultura (Unesco), em novembro de 1959, de autoria de Roger Gal, professor do Instituto Pedagógico Nacional da França, em que afirmou:

a adaptação dos programas e das estruturas do ensino secundário a um mundo onde é comum dizer-se que está em evolução acelerada, é um problema urgente que todos os países devem enfrentar, qualquer que seja seu grau de desenvolvimento. Os programas e sistemas escolares têm, certamente, em todos 
os países, um caráter nacional e muito estritamente ligado as suas tradições próprias, a seu estágio de evolução técnica, econômica e social, ao seu estatuto político, a seus fins culturais e filosóficos. E não se trata de propor soluções uniformes e eficientes para todos, uma vez que a principal lei de toda educação perfeita é estar adaptada exatamente às necessidades da sociedade na qual viverão os indivíduos que ela forma. Porém, muitos problemas comuns surgiram de uma evolução paralela, mais ou menos avançada segundo cada país, para que seja válido proceder a certa mudança de pontos de vista. (GAL, 1960, p. 19)?

Há um lapso de doze anos entre o documento da União Panamericana e os escritos de Roger Gal. Ambos tratam da reforma do ensino secundário e da importância de adaptação do ensino secundário aos ditames de uma nova época. O primeiro artigo valoriza o trabalho, tomado como a força motriz que traria ao educando uma dignidade que se construiria na escola, que até então não ampliava suas perspectivas aos desígnios históricos que associam educação a trabalho produtivo. Acreditava-se que essa associação só traria o bem do educando, ao impedir que ele despendesse tempo e energia em atividades improdutivas. No segundo artigo, a proposta de modificação do ensino secundário deveria ser adaptada ao país em que estivesse inserida, segundo suas particularidades. Cada país deveria buscar as melhores formas de adaptar o seu ensino a essas modificações, para "evoluir" em seus interesses. Nesse artigo, defende-se a ideia de contextuação do ensino a novos parâmetros, o que, neste caso, tem relação com a "evolução acelerada" e com os "graus de desenvolvimento", ou seja, com o ritmo e com o incremento empregado por cada país. Segundo essa lógica, eram considerados como fatores "universais" de mudança do ensino secundário os que poderiam ser percebidos por todo o mundo civilizado, em maior ou menor grau, dependendo do país e de seu nível tecnológico.

A diferença de doze anos entre os artigos aponta as diferenças históricas que deram configuração ao ensino secundário nos anos 1950. No final dos anos 1940, o ditame essencial para o ensino secundário dependia da introdução da visão de trabalho como forma de engrandecimento humano para os jovens. $\mathrm{O}$ ensino secundário não deveria atender a fins puramente intelectuais, mas considerar que existia uma carga de energia humana estacionada, ou mal empregada, que poderia ser produtiva e eficiente. Onze anos mais tarde, mesmo com a permanência do espectro de trabalho, a visão da educação já estava cercada por referenciais que antes não eram apontados: a visão de diversidade nacional e a importância de 
considerar tais diferenças ao estipular que tipo de educação e de legislação daria contornos a um plano nacional de desenvolvimento.

A estrutura acadêmica do secundário, o seu currículo, a didática empregada, a formação dos professores deveriam ser modernizadas. Os conteúdos de ensino deveriam ser mais bem distribuídos para atenderem ao aumento do público interessado em cursar o nível secundário. Assim, a escola modificada atenderia tanto às pressões e à necessidade dos que pleiteavam escola, quanto ampliaria a sua função formativa, ao abandonar o ensino verbalista e desconectado da realidade social, pondo em prática um ensino ágil, mais convenientemente adaptado aos novos tempos, nos quais o encurtamento das distâncias e a predominância do inglês como língua universal para fins práticos passaram a ser itens da grande mudança (RENAULT, 1959, p. 5) ${ }^{10}$.

Nos artigos publicados em 1960, é perceptível a aberta desvinculação entre o ensino secundário e a ideia de ensino propedêutico ao nível superior. $\mathrm{Na}$ Revista, o secundário era um tipo de ensino sustentado por perspectivas mais técnicas do que eruditas, mais utilitárias do que intelectuais. Os adjetivos que o qualificavam eram "amplo", "prático", "múltiplo", da forma como podemos ver, por exemplo, no texto de Gal (1960):

Ele deve considerar, tão cientificamente quanto possível, a evolução das necessidades econômicas e a divisão das tarefas na sociedade de amanhã

Ele deve mostrar quais são as ciências e as técnicas necessárias à formação do homem moderno para que ele [o jovem] se integre de modo útil na vida ativa e na sociedade adulta. Ele deve considerar as implicações sociais e humanas da especialização. E como certas ciências dizem mais respeito ao homem e a sua formação - sociologia, psicologia, pedagogia - ele deverá perguntar das consequências que essas concepções modernas podem e devem ter sobre o conteúdo e os métodos de educação. (GAL, 1960, p. 21).

O conceito de boa educação para os jovens passou a ser regulado segundo a relação estabelecida entre o processo de escolarização e o mundo do trabalho. Segundo os colaboradores da RBEP, a organização da educação do Brasil, antes mesmo do final da Segunda Guerra, “[...] vem a confundir-se com a organização do trabalho e com a renovação e o aperfeiçoamento das formas e tipos de produção [...]" (LOURENÇO FILHO, 1944, p. 18). A educação deveria ser movida para a ação, e não mais para fins intelectualistas. Embutido de um ideal racionalista, Lourenço Filho, então diretor do Inep, 
confiava na eficácia de uma moderna pedagogia, a que chamou "taylorismo educativo": "[...] maior eficiência em maximizar os resultados com o mínimo dispêndio de esforço [...]" (CARVALHO, 1999, p. 219). Ou, como disse Penteado Junior (1948, p. 49), incitar nos jovens a capacidade de "resolver por si só" os "problemas novos, que se lhe apresentem no futuro, sejam quais forem os seus problemas". O mundo era regido por uma multicomunicação de temas, práticas científicas, geográficas, históricas, sociológicas, políticas, econômicas, que o havia tornado pequeno e grande ao mesmo tempo, e não compartimentado em assuntos estanques. Se o mundo, segundo a ótica da Revista, era "complexo", deveria ser a escola um ambiente que refletisse essa complexidade.

Esse conceito de multidisciplinaridade faz convergir as óticas dos intelectuais do Centro Brasileiro de Pesquisas Educacionais (CBPE) que formulavam ideias sobre a "regionalidade" com a das "tribunas de opinião", entre as quais a RBEP, que coadjuvavam o que então se chamava de "realidade" (CUNHA, 2002, p. 35-36). De acordo com Cunha (2002), esses intelectuais estavam sob o "impacto da divulgação recente de conceitos antropológicos de cultura", o que lhes investia de um aparato novo para o entendimento da "realidade do Brasil""11. Segundo esse autor, os programas que associavam "antropologia à sociologia da educação" criaram a ideia de espaços que coexistiam com "vários tempos históricos". Como a realidade do Brasil apresentava-se diversificada pela coexistência de vários tempos históricos, entendeu-se que as leituras do Brasil não "sobreviveriam às grandes generalizações, postas até então como símbolos da cultura brasileira" e que a pesquisa educacional deveria apoiar-se nos procedimentos da pesquisa de campo a fim de que o "mapa cultural" e o "mapa educacional" do Brasil pudessem se complementar em uma explicação sociológica plausível, capaz de sustentar políticas educacionais (p. 37).

A multidisciplinaridade não era um fundamento da escola, que funcionava como uma vitrine, mais um dos centros de experimentação de uma realidade que também era nova: o Brasil dual não significava mais a distância entre a prosperidade do homem da cidade e a indolência do sertanejo. A cultura urbana, nos anos 1950, ao se fazer "vetor de racionalização" do país (CUNHA, 2002, p. 49), enxergou múltiplas culturas dentro de um mesmo universo. Portanto, a lógica de unificação não mais deveria passar pela homogeneização, como era a estratégia dos anos 1930 e 1940, mas pelo 
estudo diagnosticado desses universos paralelos. Anísio Teixeira, "espinha dorsal" desses projetos de modernização do ensino secundário, sempre defendeu a ideia de que os diagnósticos pudessem dar as coordenadas para um exercício planejado de escolarização. Anísio Teixeira tomou essa ideia de "muitos brasis" e tratou de formular um projeto educativo em que cada unidade escolar fosse um microcosmo das múltiplas diversidades brasileiras, de modo que o serviço racionalizador da escola não fosse homogêneo, mas realizado segundo as demandas diagnosticadas em cada uma das comunidades (CUNHA, 2002, p. 41-49).

Segundo Souza (1947), a ideia regional deveria ser tomada como ampla reorientação de signos para que as "padronizações" fossem abandonadas. Seria necessário, portanto, “[...] abandonar a ideia de currículos que têm de ser os mesmos para todo o Brasil, currículos que permitem apenas uma bifurcação que, na realidade, inexiste [...]" (SOUZA, 1947, p. 545). Se tempo e espaço foram redimensionados por descobertas do campo antropológico, então a própria lógica de tempo poderia ser deslocada. Havia, portanto, a hipótese de que "tempo estanque" e "tempo histórico" conviviam e que este último poderia ser deslocado ou acelerado (SOUZA, 1947, p. 41).

A Revista Brasileira dos Estudos Pedagógicos, por seu peso político, não poderia deixar de discutir a era das transformações, até mesmo porque divulgava os atos oficiais e colaborava para a difusão da mudança. As mudanças históricas são analisadas como um organismo dinâmico que teria surgido da correlação entre uma série de fatores e fenômenos sociológicos: o crescimento da população, o aumento do número de jovens, a ciência "espetacular", deificada graças à aprofundada crença em seus fundamentos, passando pelo funcionamento da técnica e a diminuição das distâncias, até o imprescindível aprendizado da língua inglesa, o que em parte justificaria a retirada do latim do currículo escolar em 1959, findando a era dos estudos clássicos. Na RBEP prevalece a ideia de que havia uma "evolução das coisas" e que, diante desse novo fenômeno, a escola secundária deveria ser transformada.

Os colaboradores da Revista criavam, com seus argumentos, um complexo de fatores que, unificados em extenso corpus histórico e documental (referências criadas em Centro de Pesquisa, estudos de entidades supranacionais, estudos estrangeiros), justificavam as transformações pelas quais deveria passar a escola secundária brasileira. O movimento de integração 
dos motivos "universais" de mudança culminou com a possibilidade de transformação do caráter do ensino secundário, por meio da alteração de seus fundamentos e de seu funcionamento.

\section{DEMOCRACIA INDUSTRIAL: O FIM DO BACHARELISMO NO ENSINO SECUNDÁRIO}

Neiva, escrevendo na seção Através de Revistas e Jornais, em 1944, já criticava a postura do ensino secundário aplicado naqueles tempos: "Não se transmite uma atitude. Muito menos uma atitude democrática". Para o autor, a "atitude democrática" deveria se mesclar ao ambiente educativo de forma que se "[...] proceda à base de efetiva cooperação em que realmente o indivíduo participe das atividades conjuntas do meio, pode formar-se essa atitude [...]" (NEIVA, 1944, p. 375).

A democracia era um bem de inestimável valor universal para os intelectuais da RBEP, e a cooperação passou a ser o elemento de destaque no ensino secundário. Essa cooperação estaria expressa na convivência entre sujeitos trabalhadores "intelectuais" e "manuais", pois essa era a aprendizagem mais fecunda para a "formação do homem atual" (LARREA, 1947, p. 419). Larrea reclamava uma educação que valorizasse o trabalho manual, apontando a sua falta em toda a América Latina. Tornar o ensino secundário um canal para atividades vocacionais era um problema universal.

Em 1954, Anísio Teixeira explicava para os inspetores de ensino que o caráter de escola para formar uma elite mandatária estaria em extinção, porque a comunidade que estava presente nesse tipo de ensino já não era mais composta pela aristocracia brasileira. O que existia era um "fenômeno de massa", que estava tomando a escola das elites como condição para a ampliação de sua expectativa particular de ascensão social. Portanto, uma heterogeneidade social estaria forçando a escola a desenvolver novas técnicas, já que não se tratava mais de educar alguns poucos, mas educar a todos (TEIXEIRA, 1954, p. 9-10). Sobre esse aspecto, era necessário ter "uma compreensão mais perfeita da cultura de nossa época" (p. 10) e entender a escola secundária como um local que oferecesse "aos seus alunos a mais variada gama de oportunidades educativas, capazes de formá-los de acordo com suas aptidões e capacidades", pois a escola moderna não tinha 
pretensão de fazer de seus alunos "todos intelectuais". A regra de ouro da nova escola baseava-se na seguinte premissa: "ensinar pouco e bem". $\mathrm{O}$ estudante dependeria da "inteligência compreensiva", seria "autodidata", "aprenderia por si" sem ser "adestrado", porque, no fim da jornada, cada aluno viveria segundo "o que cada um adquiriu na sua luta livre pela educação” (TEIXEIRA, 1954, p. 11).

Anísio Teixeira critica o ensino das humanidades clássicas, porque o ensino secundário clássico tratou de criar uma pequena elite de pessoas "cultas", "intelectuais", em descompasso com um novo tipo de humanismo que, segundo ele, agregava as três formas de educação secundária: a literária, a técnica e a científica ${ }^{12}$. Segundo o autor, os jovens deveriam ter em mãos "a posse de um instrumental de trabalho" que os habilitasse a ter uma visão dos conhecimentos de forma correlacionada (TEIXEIRA, 1954, p. 7). Desse modo, ação e disciplina, propugnados com métodos racionais e científicos de ensino, possibilitariam tanto a criação de um novo homem, autônomo e capaz, quanto ampliariam as possibilidades de ascensão social e de conhecimento e práticas humanas. Em vez de existir uma única elite, poder-se-ia assistir ao surgimento do que chamava de "pequenas elites": vários pequenos agrupamentos selecionados por competências particulares, que comporiam as várias "microssociedades", que gozariam dos conhecimentos adquiridos e, por conseguinte, agiriam pelo bem da sua comunidade ou em sociedade (TEIXEIRA, 1954, p. 14).

Em 1956 o autor desenvolveu o tema "Os processos democráticos da educação dos diversos graus de ensino e na vida escolar" ${ }^{13}$, explicando o conceito de sociedade democrática produzida na escola, em que estavam aliadas ideias de "cooperação", "vida comunitária", "respeito mútuo", "igualdade humana" e "progresso social". Para o pensador, a nova democracia seria amparada pela cooperação: uma ajuda mútua entre as pequenas elites. Sobre como deveria ser a verdadeira experiência democrática dentro do ambiente escolar, manifestou-se favorável à "divisão de tarefas" e à formação de um "team" entre alunos, professores e a administração escolar, em que "todos se sintam tão bons quanto os outros” (TEIXEIRA, 1956, p. 14).

Com a abertura do CBPE e dos Centros Regionais, em 1955, os artigos da Revista tomam outro rumo, uma vez que a perspectiva interpretativa da ciência econômica passa a ser crivo das análises sobre educação ${ }^{14}$. De acordo com Freitas (2001), a Unesco “[...] como agência para o desenvolvimento da 
educação, da ciência e da cultura, junto à organização das Nações Unidas, tece papel fundamental na reformulação das ciências sociais e da pesquisa educacional do país."

A entrada da Unesco no Brasil, em 1949, foi decisiva para a reformulação das ciências sociais e para as pesquisas educacionais no Brasil (FREITAS, 2001, p. 33-34).

Predomina, então, a ideia de que o desenvolvimento era a essência da "evolução das coisas", e que a educação deveria integrar planos de desenvolvimento. A funcionalidade da escola com propósito de desenvolvimento foi o tema de um artigo escrito por Lourenço Filho. O educador teceu uma ideia de movimento da sociedade brasileira rumo ao desenvolvimento, explicando que educaşão para o desenvolvimento era diferente de educaşão e desenvolvimento (LOURENÇO FILHO, 1961, p. 44). Para o autor, o desenvolvimento era um vetor que levaria os brasileiros a um "maior equilíbrio das relações humanas", admitindo uma "sociedade nacional" em que os indivíduos e as instituições estivessem unidos com "partes e subpartes" integradas e articuladas, demonstrando ser o desenvolvimento um processo "multicausal, cumulativo e circular", que "implica realidade de infraestrutura” (LOURENÇO FILHO, 1961, p. 37) 15. Os indicativos de desenvolvimento pleno seriam o "bem-estar social", compreendido como "sistema de valores igualitários no que toque o exercício de direitos", e o "bem-estar econômico", entendido como "mobilidade social no sentido vertical”. Para Lourenço Filho (1961, p. 46), a existência da classe média era o maior indicador do aumento de bem-estar econômico, pois demonstrava o aumento da riqueza de uma nação ${ }^{16}$. O bem-estar social estava atrelado a poder de compra e ganho monetário e, como tal, acabava sendo o maior indicativo de democracia, já que era por meio dela que se chegaria ao desenvolvimento (LOURENÇO FILHO, 1961, p. 45). Para o autor, o Brasil estaria passando pela fase de "educação para o desenvolvimento", motivo pelo qual estaria sujeito a "doutrinas e ideologias relativas à organização política”, ou à "educação social para a mudança” (p. 37). O autor previa o desenvolvimento dessa fase como "dependente do funcionamento ordenado de um sistema econômico e afirmava que essa ordenação requereria uma distribuição equilibrada de trabalhadores pelos diferentes grupos profissionais" (p. 38). Por esse motivo, a ação educativa bem executada (p. 46) seria aquela que formasse os "requisitos educativos da força de trabalho 
destinada à produção", já que deveriam ser levadas em conta as "exigências da estrutura profissional", as "transformações da estrutura profissional" nas "novas mudanças na estrutura de pessoal" e o "progresso técnico" de cada país (p. 38-39).

Anísio Teixeira também tratou do desenvolvimento durante o Encontro Regional de Educadores Brasileiros, em $1961^{17}$, estabelecendo sua relação com o tipo de liderança eclética que passou a chefiar a transformação (TEIXEIRA, 1961, p. 72). Ao longo do texto, explica que era possível observar o desenvolvimento dos países acompanhando o desempenho dos grupos sociais que estivessem no poder, bem como o funcionamento das relações entre as classes sociais dentro de uma dada nação. Segundo o texto, quanto mais equilíbrio houvesse entre as classes, maior desempenho teria o país com relação ao processo de desenvolvimento. A tônica do artigo é o processo de industrialização, como "profundamente dinâmico, implacável, irreversível” (p. 72). Para o pensador baiano, o desenvolvimento estava relacionado com a classe média por ser ela a classe mais aparelhada em “ideias específicas relativas à nova ordem industrial”. A classe média, essa "nova elite", o padrão homogeneizador que indicaria o desenvolvimento do país, porque, neste caso, o "bem-estar social" estaria equalizado. Por ser "motivada pela ação", essa classe não admitiria os ditames aristocráticos que atribuiriam tão pouco valor a uma de suas funções, que é trabalhar.

Eis aqui mais uma das noções de "desajuste" da escola secundária apresentada pela RBEP. A escola tradicional não abria chance para que houvesse o amadurecimento da classe média que pressionava pelo ensino secundário, por compreendê-lo como um veículo de crescimento econômico, indicativo maior de desenvolvimento. Assim, recaía sobre a escola secundária para "bacharéis" mais uma culpa: a de ser inibidora do processo de enriquecimento dessa classe que, pelos discursos de RBEP, tornou-se um termômetro da riqueza nacional. Estratificada nos moldes do ensino preparatório, a escola secundária teria criado um grande "desajuste" na educação brasileira, porque o padrão de preparação das "individualidades condutoras", via prestigiosa de acesso à ascensão social, já não combinava com os interesses e necessidades da população discente naquele momento histórico. A desarticulação do ensino secundário para bacharéis também eliminaria o problema do excesso de matrículas que nele se avolumavam. 
Ao menos quantitativamente, os órgãos governamentais poderiam se livrar de um "entrave social".

Segundo Cunha (2002, p. 130), a ideologia desenvolvimentista que predominou em quase toda a segunda fase dos artigos de RBEP deslocou o debate "da área política para a área econômica". Ao visarem ao "bem-estar social", os discursos aliados à política econômica conclamavam "todos os brasileiros" à luta pelo progresso do país, prevalecendo a "harmonia entre capital e trabalho", demonstrando que cada um deveria oferecer ao país aquilo que dispusesse, "seja capital, seja trabalho". Portanto, ricos e pobres, separados por fronteiras de classe social, "estariam unificados" porque ambas as contribuições seriam de extremo valor. $\mathrm{O}$ desenvolvimento econômico passava a ser chave para um "futuro melhor". O homem almejado para a entrada do Brasil no mundo de civilização industrial deveria ter a "preparação técnica de nível médio" (CUNHA, 2002, p. 130-132).

\section{CONSIDERACְÕES FINAIS}

Nos anos 1950, a vertente interpretativa que produziu a ideia de um mundo urbano como estimulador das transformações remanescentes do mundo rural apareceu amplificada. O crescimento urbano-industrial e o aumento da população eram elementos que a RBEP continuamente indicava como fatores para uma expressiva mudança do formato da escola. De acordo com esses colaboradores, o subdesenvolvimento era um pesadelo remanescente do período latifundiário, que tinha por ideal uma sociedade rural e aristocrata. Por isso, escola boa, de qualidade, moderna, deveria ter formas e técnicas que desenvolvessem o sentido da prática cidadã nos modelos de uma democracia industrial (ABREU, 1960, p. 12).

Não é de se estranhar o uso da expressão "democracia industrial", que associa novos significados ao termo "democracia". Isto é, um movimento em que estava em jogo a contribuição do cidadão para com a evolução do seu país, independentemente de sua classe social, tendo no trabalho o elo aglutinador. O ensino médio seria um veículo de aglutinação de ideais, um elemento que agruparia os seres heterogêneos cujas capacidades diferenciadas poderiam ser selecionadas na escola. Ao serem selecionadas por competências, não se estaria mais a falar de grupos sociais, mas de uma 
coletividade agregada em favor do bem-estar geral. Pensando dessa forma, não haveria mais motivos para qualificar o ensino secundário como o único ramo de ensino prestigioso, já que até mesmo a ideia de prestígio teria sido deslocada do intelectualismo para o trabalho. A democracia e o capitalismo industrial são vistos como um jogo de espelhos, tanto internacionalmente, por conta da Guerra-Fria e da influência norte-americana sobre a América Latina, acentuadamente nos campos de pesquisa, quanto nacionalmente, quando se exacerbava o desenvolvimentismo.

As ciências sociais, ao tempo em que introduziam conceitos capazes de capturar e interpretar essas modificações estruturais, colaboravam para o planejamento de uma escola adequada às realidades locais. Sociologia, Psicologia e Pedagogia adentraram a discussão da reforma do secundário em RBEP, introduzidas como ciências fundamentais para um ensino novo. Fizeram-se presentes, conferindo bases científicas a teses, organizando racionalmente as necessidades físico-estruturais ou intelectual-filosóficas da escola moderna, demonstrando os benefícios da aplicação de suas metodologias para o assessoramento funcional da educação.

Portanto, no plano nacional, a escola secundária era entendida como mais um dos segmentos do grande plano de "integração nacional" e, ao mesmo tempo, como mais um dos aparatos reguladores das populações que viviam sob as políticas populistas e diante da "instabilidade institucional" do país. O ensino secundário deveria ser a mola central do direcionamento social da juventude por suas "vocações" e "competências" para uma sociedade democrática e em mudança contínua. O formato clássico, destinado a uma população seleta e voltado para a formação de elites condutoras, já se encontrava decadente e anacrônico. Em seu lugar, mais adequado a uma sociedade democrática e industrial, que naquele momento era mais pretendida do que vivida, a RBEP projetava um ensino dinâmico, ativo, articulado aos interesses das comunidades, motivado e propenso ao trabalho útil e produtivo. 


\section{REFERÊNCIAS}

ABREU, J. Tendências antagônicas do ensino secundário brasileiro. Revista Brasileira de Estudos Pedagógicos, Brasília, v. 33, n. 78, p. 3-18, abr./jun. 1960.

BRAGHINI, K. M. Z. O ensino secundário brasileiro nos anos 1950 e a questão da qualidade de ensino. 2005. 164. Dissertação (Mestrado em Educação)-Pontifícia Universidade Católica de São Paulo, São Paulo, 2005.

BRASIL. Instituto Nacional de Estudos Pedagógicos. "Editorial". Revista Brasileira de Estudos Pedagógicos, Rio de Janeiro, v. 9, n. 25, p. 227-228, nov./dez. 1946.

CARVALHO, M. M. C. O Território do consenso e a demarcação do perigo: política e memória do debate educacional dos anos 30. In: FREITAS, M. C. (Org.). Memória Intelectual da Educação Brasileira. Bragança Paulista: Editora Universidade São Francisco, 1999. p. 17-33. CUNHA, M. V. A Educação no período Kubitscheck: os Centros de Pesquisa do Inep. Revista Brasileira de Estudos Pedagógicos, Brasília, v. 83, n. 203-205, p. 127-140, jan/dez. 2002. DUTRA, E. G. Exposição do programa de governo aos baianos. Revista Brasileira de Estudos Pedagógicos, Brasília, v. 4, n. 19, p. 5-16, jan. 1946.

FREITAS, M. C. História, antropologia e pesquisa educacional: itinerários intelectuais, São Paulo: Cortez, 2001.

GAL, R. O ensino secundário e o mundo moderno. Revista Brasileira de Estudos Pedagógicos, Brasília, v. 33, n. 78, p. 19-27, abr./jun. 1960.

GANDINI, R. P. C. Intelectuais, Estado e Educação: Revista Brasileira de Estudos Pedagógicos, 1944-1952. Campinas: Editora UNICAMP, 1995.

LARREA, J. Espírito, tendências e problemas da educação latino-americana. Revista Brasileira de Estudos Pedagógicos, Brasília, v. 10, n. 28, p. 410-425, maio/jun. 1947.

LOURENÇO FILHO, M. B. Educação para o desenvolvimento. Revista Brasileira de Estudos Pedagógicos, Brasília, v. 3, n. 81, p. 35-66, jan./mar. 1961.

LOURENÇO FILHO, M. B. A educação, problema nacional. Revista Brasileira de Estudos Pedagógicos, Brasília, v. 1, n. 1, p. 7-28, jul. 1944.

NEIVA, Á. A escola secundária e a formação de atitudes democráticas. Revista Brasileira de Estudos Pedagógicos, Brasília, v. 1, n. 3, p. 371-375, set. 1944.

NUNES, Z. C. R. M. O "velho" e "bom" ensino secundário: momentos decisivos. Revista Brasileira de Educação, São Paulo, n. 14, p. 35-60, maio-ago. 2000.

PENTEADO JUNIOR, O. O governo semi-autônomo da escola secundária e a educação cívico-moral. Revista Brasileira de Estudos Pedagógicos, Brasília, v. 12, n. 32, p. 45-49, jan./ abr. 1948.

RENAULT, A. A escola secundária de ontem e a escola secundária de hoje. Revista Brasileira de Estudos Pedagógicos, Brasília, v. 32, n. 75, p. 3-13, jul./set. 1959.

SAAVEDRA, S. M. G. Passos e Descompassos de uma Instituição de Pesquisa Educacional no Brasil: A realidade do INEP. 1988. 279 f. Dissertação (Mestrado)-Faculdade de Educação, Universidade de Brasília, Brasília, 1988.

SOUZA, F. T. O problema do ensino secundário. Revista Brasileira de Estudos Pedagógicos, Brasília, v. 10, n. 28, p. 545-546, maio/jun. 1947. 
SPÓSITO, M. P. O Povo vai à escola: a luta popular pela expansão do ensino público em São Paulo. São Paulo: Loyola, 1984.

TEIXEIRA, A. Discurso de posse do professor Anísio Teixeira no Instituto Nacional de Estudos Pedagógicos. Catálogo da Revista Brasileira de Estudos Pedagógicos, Brasília, v. 1-26, n. 1-44, p. 69-79, jul./dez. 1952.

TEIXEIRA, A. A escola secundária em transformação. Revista Brasileira de Estudos Pedagógicos, Brasília, v. 25, n. 62, p. 3-20, abr./jun. 1954.

TEIXEIRA, A. O processo democrático de educação. Revista Brasileira de Estudos Pedagógicos, Brasília, v. 25, n. 62, p. 3-16, abr./jun. 1956.

TEIXEIRA, A. Educação e desenvolvimento. Revista Brasileira de Estudos Pedagógicos, Brasília, v. 35, n. 81, p. 71-92, jan./mar. 1961.

UNIÃO PANAMERICANA. Pela reforma da escola secundária. Revista Brasileira de Estudos Pedagógicos, Brasília, v. 11, n. 30, p. 225-241, set./out. 1947.

VARGAS, G. A mensagem presidencial de 1952 e a educação. Revista Brasileira de Estudos Pedagógicos, Brasília, v. 17, n. 45, p. 199-210, jan./mar. 1952.

\section{NOTAS}

1 A RBEP é uma revista editada por um dos mais importantes órgãos ligados à Educação do país, o Instituto Nacional de Estudos Pedagógicos (Inep). Publicada desde 1944, continua sendo editada pelo mesmo órgão governamental, por cinquenta anos sem interrupções. A RBEP é um compêndio de artigos, leis, pensamentos, técnicas e atividades produzidos por vários órgãos do MEC e recolhidos pela divisão de Documentação e Informação Pedagógica. É um extrato de toda a ordenação governamental que diz respeito à educação brasileira. Não era meramente a divulgação das produções estudadas e pesquisadas por órgãos governamentais, estabelecendo diretrizes políticas para a Educação, mas atuava como um registro dos possíveis ditames do governo, feito por profissionais que atuavam diretamente em órgãos estatais voltados aos estudos sobre a educação brasileira. Na verdade, como intelectuais e técnicos, esses colaboradores foram os articuladores de uma política educacional, na medida em que eram colocados estrategicamente em postos de trabalhos ligados às direções e atuando para o funcionamento das entidades voltadas para a pesquisa, de modo que o levantamento de dados e a proposição de um ideal de país ligavam-se aos acontecimentos do país. Nos anos 1950, a RBEP tendia a ser trimestral, mas, às vezes, era editada por bimestre e, ainda, lançava números especiais intercalados à publicação regular.

2 Independentemente da seção escolhida, todos os artigos foram estudados por meio da análise dos seus discursos. Eram selecionadas as informações que explicassem o significado da qualidade do ensino secundário nos anos 1950.

3 O primeiro número da RBEP saiu em julho de 1944. 
4 Para saber mais, Braghini (2005). O ensino secundário nos anos 1950 e a questão da qualidade de ensino. Dissertação de Mestrado em Educação: História, Política e Sociedade, Pontifícia Universidade Católica de São Paulo, 2005 em http://www.sapientia.pucsp.br.

5 A Lei Orgânica do Ensino Secundário (Decreto-Lei no . 4.244/1942), promulgada sob o mandato de Gustavo Capanema no Ministério da Educação e Saúde, definiu o ensino secundário como ramo exclusivo de passagem para o ensino superior. O ensino médio brasileiro possuía os níveis ginasial (4 anos) e colegial (3 anos), divididos nos cursos secundário, industrial, comercial, rural e normal, cada qual regido por legislação particular. Com exceção ao ensino secundário, todos os outros cursos eram terminais e, portanto, não conduziam seus egressos às universidades.

${ }^{6}$ Dois estudos indicam que os legisladores tinham interesses dissonantes com relação ao que, sobre o ensino secundário, vinculava-se na RBEP. Nunes (2000, p. 46) observa que a educação tornou-se uma espécie de barganha entre as classes médias e populares, de modo que os líderes populistas, pressionados, tornaram a "educação escolarizada" e a abertura de ginásios públicos "uma bandeira de luta”. Spósito (1984, p. 135), tendo estudado as lutas populares e a abertura de ginásios públicos em São Paulo, afirma que teria havido nesse processo "ineficácia da Assembleia legislativa, somada à 'ausência de diretrizes educacionais"”. Segundo a autora, uma das críticas de O Estado de S.Paulo, à época, era a prática política de se abrir ginásios indiscriminadamente, porque, "do ponto de vista eleitoral”, essa fórmula era "mais vantajosa" do que abrir escolas primárias.

7 Ao incluir a sigla RBEP, como "autoria" aponta-se para textos em um corpo editorial se apresenta como representante da edição, na maior parte das vezes, o texto foi publicado na forma de "editorial".

8 Jaime Abreu era diretor do Centro Brasileiro de Pesquisas Educacionais (CBPE), quando proferiu as palestras no Colégio Estadual da Bahia e no Centro Regional de Pesquisas Educacionais de Recife em 1960. Nelas, citou I.L. Kandel, professor do Teachers College da Universidade de Columbia, em Uma Nova Era da Educaşão.

9 O artigo de Roger Gal foi publicado na França em 1959 em La Chronique de l'Unesco e depois traduzido, em 1960, para a RBEP.

10 Palestra inaugural dos cursos do Colégio D. Pedro II, em 1959.

11 Auxiliados por J. Lambert e O. Klineberg, no ano de 1956, técnicos da Unesco, os diretores do CBPE elaboraram um plano de ação para o Centro nos anos 1956-1957.

12 Segundo Teixeira (1961, p. 11), o conceito de humanismo havia sido ampliado, passando a ter um sentido corporativo que desbancaria o conceito de trabalho como uma mobilização específica dos que estavam à margem da cidadania. Os indicadores de escola ruim ainda estavam ligados à formação elitizada, portanto, "velha"; educação de "alisar bancos". Para o educador, o preconceito para com uma escola mais prática dizia respeito à permanência de um ranço aristocrático na verve do brasileiro médio.

13 Palestra feita na XII Conferência Nacional de Educação, promovida pela Associação Brasileira de Educação (ABE). 
14 O Centro Brasileiro de Pesquisas Educacionais (CBPE), criado pelo Decreto-lei ${ }^{\circ}$. 38.460 em 28/dez/1955 - instituído pelo Ministro Abgar Renault, foi idealizado por Anísio Teixeira, então diretor-geral do Inep. Esse órgão foi criado com intenção de integrar as atividades de pesquisa e documentação, para facilitar o trabalho de consulta, organização e posterior divulgação de ideias relacionadas à educação, tendo por objetivo fundar uma educação de bases científicas, associada ao intercâmbio entre pesquisadores nacionais e internacionais, envolvido com projetos da Organização das Nações Unidas para a Educação, a Ciência e a Cultura (Unesco).

15 Esse foi o conceito de desenvolvimento valorizado pelo autor, adotado pela Unesco para a Conferência Interamericana sobre Educação e Desenvolvimento Social e Econômico, realizada em novembro de 1959.

${ }^{16}$ Riqueza, para Lourenço Filho (1961, p. 45), era a média resultante dos seguintes índices: "[...] a renda per capita, o número de pessoas por médico e por veículo motorizado, e o número de rádios receptores, telefones e exemplares de jornal por mil pessoas [...]”.

${ }^{17}$ Foram referências para a palestra do educador baiano: Inter-university Study os Labor Problems in Economics Development, organização criada, em 1954, pelos economistas Clark Kerr, Jonh T. Dulop, Frederick Harbinson e Charles A. Myers. O livro do grupo é Industrialism and Industrial Man, publicado pela Harvard University Press, Cambridge, Mass. USA, 1960.

Recebido: 08/11/2011 Aprovado: 04/06/2012 